\title{
Climatic characteristics of the tropopause over the Arctic Basin
}

\author{
A. P. Nagurny \\ Arctic and Antarctic Research Institute, 38 Bering Street, St. Petersburg, 199397, Russia, \\ e-mail: aaricoop@sovam.com
}

Received: 22 April 1996 / Revised: 16 June 1997 / Accepted: 1 July 1997

\begin{abstract}
On the basis of stationary aerological observations and measurements at Russian "North Pole" drifting stations taken during 1954-1991, tropopause climate parameters (height and temperature at its upper and lower bounds) are determined. Long-term trends of these parameters over the Arctic Ocean are revealed.
\end{abstract}

Key words. Meteorology and atmospheric dynamics • Climatology $\cdot$ Polar meteorology

\section{Introduction}

The tropopause as a transient layer between the troposphere and stratosphere is extremely important while studying climate and circulation of free atmosphere. This layer affects the exchange of vapour, ozone and aerosols between the troposphere and stratosphere. Some researchers (Danielson, 1968; Karol, 1972; Hofmann et al., 1974; Mahover, 1983; Timerev et al., 1994, Alekseev et al., 1994; Holton et al., 1995) point out specific features of aerosol transport through the tropopause. Thus, through studying of the tropopause is important both for pure scientific and applied purposes.

There are several works dedicated to the structure and dynamics of the Arctic tropopause (Gaigerov, 1964; Mahover, 1973, 1983; Goldied et al., 1958). In these investigations, spatial and temporal distributions of height and air temperature at upper (Mahover, 1983) and lower tropopause bounds in the Arctic region are envisaged. At present a broad data collection is gathered comprising observations within the total period of operation of the "North Pole" drifting stations in different regions of the Arctic Ocean. This collection is more complete than data sets previously available.

\section{Data recording and methodology}

In the present investigation, we analyse daily aerological observations (two probes per day) at the North Pole drifting stations, covering all months of the year in the time-interval 1950 and 1954-1991. Observational data processing was carried out by composing them in solitary series of varying duration, according to method introduced in Nagurny (1995). An area between $70^{\circ}$ and $85^{\circ} \mathrm{N}$ was divided into approximately equal rectangles $\left(319 \mathrm{~km}^{2}\right)$. The region near to the pole is divided into two equal sections approximately 1.5 times bigger than the neighbouring squares (Fig. 1 of Nagurny, 1995).

The obtained observational series length varied between 1 and 18 years. Aerological observations accomplished before June 1957 were improved using a radiation correction term, which could be about $2^{\circ}-2.5^{\circ}$ (Methodical notes, 1960) at $8-11 \mathrm{~km}$ height for a sun zenith angle of about $45^{\circ}$. Introduction of the correction term was caused by change of the radiosonde type in 1957 in the USSR.

Formal criteria of the tropopause layer determination were developed by the Commission for Aviation Meteorology of the World Meteorological Organisation (WMO) in 1953. The criteria were revised at the second session of this commission in 1957. According to these criteria, the definition of tropopause type is based on the vertical temperature gradient value and variation of this parameter within the tropopause.

A typical tropopause layer and temperature distribution within it is presented in Fig. 1. Three major types of temperature change within the transient zone between the troposphere and stratosphere can be distinguished: inverse, isothermal and sharp decrease in positive meteorological gradient with retention of weak positive gradient in the stratosphere.

The tropopause is defined as the lowest level above the $500-\mathrm{hPa}$ isobaric surface, where vertical temperature gradient decreases to $2{ }^{\circ} \mathrm{C} / \mathrm{km}$ or less on condition that average vertical gradient in the upper 2000-m layer is less than $2{ }^{\circ} \mathrm{C} / \mathrm{km}$. 

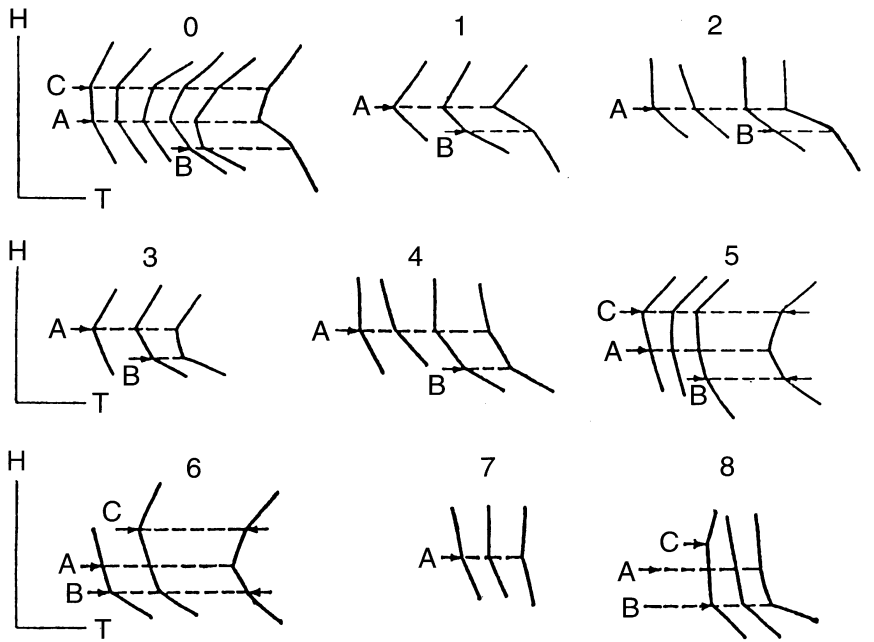

7
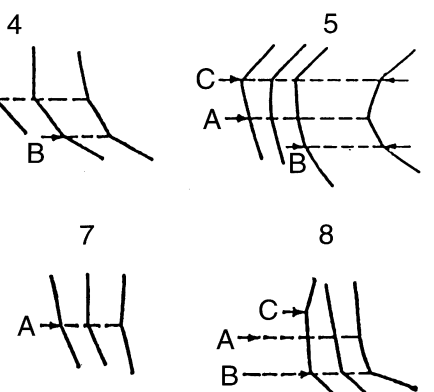

8

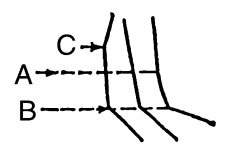

Fig. 1. Tropopause types and change of vertical temperature gradient within the tropopause (A - tropopause level, B and $\mathrm{C}-$ lower and upper tropopause bounds)

Sometimes, the lower tropopause bound is determined simultaneously with the upper bound. The upper tropopause bound is defined as the level where a thicker isothermal layer or weak temperature change begin. Mean vertical temperature gradient is determined as the ratio of temperature difference between the bounds to the layer thickness and is independent of temperature distribution within the tropopause.

Taking into account the specific arctic conditions, the $600-\mathrm{hPa}$ reference level was chosen as the lowest possible location of tropopause lower bound, rather than the $500-\mathrm{hPa}$ level recommended by the Commission for Aerology (1957). An upper tropopause bound was associated with the height of transition to thick (more than $2 \mathrm{~km}$ ) inverse or isothermal layer, or the height of transition to weak (less than $1{ }^{\circ} \mathrm{C} / \mathrm{km}$ ) air temperature decrease or increase. In the multiple tropopause case only the lowest one was envisaged.

An analysis of daily height and temperature tropopause evolution was accomplished on the basis of the North Pole drifting station aerological probes inside the rectangle $80^{\circ}-85^{\circ} \mathrm{N}, 160^{\circ} \mathrm{E}-160^{\circ} \mathrm{W}$, where observational series length exceeded 7 years. Every day, radiosonde probes at 00 and 12 GMT for January, March, July and October were analysed. According to calculations, monthly averages of daily variations in upper and lower tropopause bound heights did not exceed 0.27 and $0.39 \mathrm{~km}$, respectively, while the average air temperature variation at these levels was $1.3^{\circ}$ and $1.4{ }^{\circ} \mathrm{C}$. Day-to-day changes in tropopause height exceed their daily variations by 4-6 times, while for tropopause temperature an analogous relation is $2-3$. The latter points to the prior influence of circulation on the tropopause conditions in comparison with the radiative effect.

In order to obtain climate values of arctic tropopause temperature and height minimal data series length, providing suitable accuracy was evaluated, calculations were carried out for seven rectangles in the Arctic Basin (Nagurny, 1995). Within each rectangle there was an observational series of between 5 and 18 years duration and accuracy $0.2 \mathrm{~km}$ and $1{ }^{\circ} \mathrm{C}$ for tropopause height and temperature, respectively. Such accuracy corresponds to approximately $2 \%$ of the mean value.

An investigation demonstrated that a 4-5-year-long observational series allows to obtain reliable climatic temperature values on the upper and lower bounds as well as the value of lower tropopause height with the accuracy just described. From December to February, when the winter meridional processes are rather active, the precision of climate temperature and height estimations are $1.3{ }^{\circ} \mathrm{C}$ and $0.25 \mathrm{~km}$, respectively. In the springautumn period, climatic value of the upper tropopause bound is evaluated with the same precision.

\section{Data analysis}

An analysis of monthly average tropopause height and temperature in winter (January) and in summer (July) seasons demonstrates rather weak latitudinal variations of these parameters (see Table 1). The variation coefficients of monthly average air temperature in that tropopause upper bound in January, as well as the upper bound's height variation in January, exceed analogous values calculated for its lower bound. This circumstance points to more active interlatitudinal exchange in the lower part of the arctic stratosphere in comparison with its upper part. In summer, the variation coefficient of the tropopause lower bound exceeds the changes in the upper bound due to the intensification of convection above the Arctic Basin. Seasonal oscillations of studied tropopause parameters in different regions of the Polar Ocean depend on the intensity of circulation conditions in the region and radiation effects.

Annual evolution of tropopause height and temperature was studied on the basis of long-term North Pole aerological measurements within the region, limited by coordinates $70^{\circ}-90^{\circ} \mathrm{N}, 80^{\circ} \mathrm{E}-110^{\circ} \mathrm{W}$. Monthly average values of these parameters were composed within $5^{\circ}$ latitudinal belts. Annual evolution of air temperature at lower and upper tropopause bounds within the examined tropopause layer is characterized by one maximum (in July) and minimum in December-January. The existence of these extrema is connected with annual cycling of solar radiation, convective activity, cloudiness and long-wave atmospheric backward radiation (see Fig. 2). The tropopause temperature maximum in June, pointed out in Gaigerov (1964) Mahover (1983), was not revealed.

Annual temperature amplitude at the tropopause level increases with latitude and in $70^{\circ}-90^{\circ}$ latitudinal strip lies within the margins $10^{\circ}-14^{\circ} \mathrm{C}$ and $13^{\circ}-21^{\circ} \mathrm{C}$ for lower and upper tropopause bounds, respectively. Annual amplitudes which characterize marginal temperature values are caused first of all by the factor of radiation - polar day and night seasonal alternation. This is the reason for the existence of seasonal mean air temperature extrema at the near-pole tropopause. 
Table 1. Mean values $(X)$ of height $(h \mathrm{~km})$ and air temperature $\left(t^{\circ} \mathrm{C}\right)$ at the lower $(\mathrm{L})$ and upper $(\mathrm{H})$ tropopause bounds, variation coefficient $(V \%)$ of these parameters

\begin{tabular}{|c|c|c|c|c|c|c|c|c|c|c|c|c|}
\hline \multicolumn{2}{|c|}{ coordinates } & \multirow[t]{2}{*}{ parameter } & \multicolumn{4}{|c|}{ January } & \multirow{2}{*}{$\begin{array}{l}\text { no. of } \\
\text { years }\end{array}$} & \multicolumn{4}{|l|}{ July } & \multirow{2}{*}{$\begin{array}{l}\text { no. of } \\
\text { years }\end{array}$} \\
\hline${ }^{\circ} \mathrm{N}$ & ${ }^{\circ} \mathrm{E}, \mathrm{W}$ & & $h_{\mathrm{L}}$ & $h_{\mathrm{H}}$ & $t_{\mathrm{L}}$ & $t_{\mathrm{H}}$ & & $h_{\mathrm{L}}$ & $h_{\mathrm{H}}$ & $t_{\mathrm{L}}$ & $t_{\mathrm{H}}$ & \\
\hline \multirow[t]{2}{*}{$75-80$} & $150 \mathrm{E}-$ & $X$ & 9.23 & 11.32 & -62.2 & -60.3 & \multirow[t]{2}{*}{10} & 9.69 & 11.59 & -49.2 & -41.9 & \multirow[t]{2}{*}{8} \\
\hline & $175 \mathrm{E}$ & $V$ & 5.6 & 7.9 & 5.6 & 7.9 & & 6.0 & 5.2 & 4.4 & 4.9 & \\
\hline \multirow[t]{2}{*}{$75-80$} & $175 \mathrm{E}-$ & $X$ & 8.81 & 11.15 & -59.8 & -58.1 & \multirow[t]{2}{*}{7} & 9.60 & 11.53 & -49.3 & -42.6 & \multirow[t]{2}{*}{14} \\
\hline & $160 \mathrm{~W}$ & $V$ & 6.8 & 6.9 & 6.4 & 8.9 & & 4.8 & 4.1 & 3.6 & 4.4 & \\
\hline \multirow[t]{2}{*}{$80-85$} & $120 \mathrm{E}-$ & $X$ & 8.80 & 10.74 & -61.3 & -59.9 & \multirow[t]{2}{*}{6} & 9.71 & 11.48 & -50.0 & -42.2 & \multirow[t]{2}{*}{8} \\
\hline & $160 \mathrm{~W}$ & $V$ & 3.6 & 6.8 & 2.5 & 3.6 & & 4.4 & 4.3 & 4.0 & 4.4 & \\
\hline \multirow[t]{2}{*}{$80-85$} & $160 \mathrm{E}-$ & $X$ & 8.76 & 10.91 & -60.4 & -58.5 & \multirow[t]{2}{*}{14} & 9.38 & 11.27 & -48.8 & -41.5 & \multirow[t]{2}{*}{16} \\
\hline & $160 \mathrm{~W}$ & $V$ & 4.2 & 6.5 & 4.6 & 7.0 & & 4.3 & 3.9 & 3.0 & 3.8 & \\
\hline \multirow[t]{2}{*}{$80-85$} & $120 \mathrm{~W}-$ & $X$ & 8.99 & 11.12 & -60.7 & -58.6 & \multirow[t]{2}{*}{9} & 9.44 & 11.27 & -49.0 & -41.3 & \multirow[t]{2}{*}{7} \\
\hline & $160 \mathrm{~W}$ & $V$ & 4.1 & 4.4 & 5.7 & 9.1 & & 6.7 & 4.1 & 6.3 & 6.4 & \\
\hline \multirow[t]{2}{*}{$85-90$} & $90 \mathrm{E}-$ & $X$ & 9.02 & 10.96 & -62.6 & -61.0 & \multirow[t]{2}{*}{14} & 9.30 & 11.13 & -48.2 & -40.7 & \multirow[t]{2}{*}{10} \\
\hline & $90 \mathrm{~W}$ & $V$ & 3.4 & 4.8 & 4.8 & 7.1 & & 3.2 & 3.2 & 3.9 & 4.7 & \\
\hline \multirow[t]{2}{*}{$85-90$} & $90 \mathrm{~W}-$ & $X$ & 9.02 & 10.91 & -62.8 & -61.5 & \multirow[t]{2}{*}{9} & 9.30 & 10.95 & -48.2 & -40.3 & \multirow[t]{2}{*}{5} \\
\hline & $90 \mathrm{E}$ & $V$ & 5.8 & 6.1 & 4.1 & 5.6 & & 4.9 & 4.1 & 5.0 & 5.1 & \\
\hline
\end{tabular}

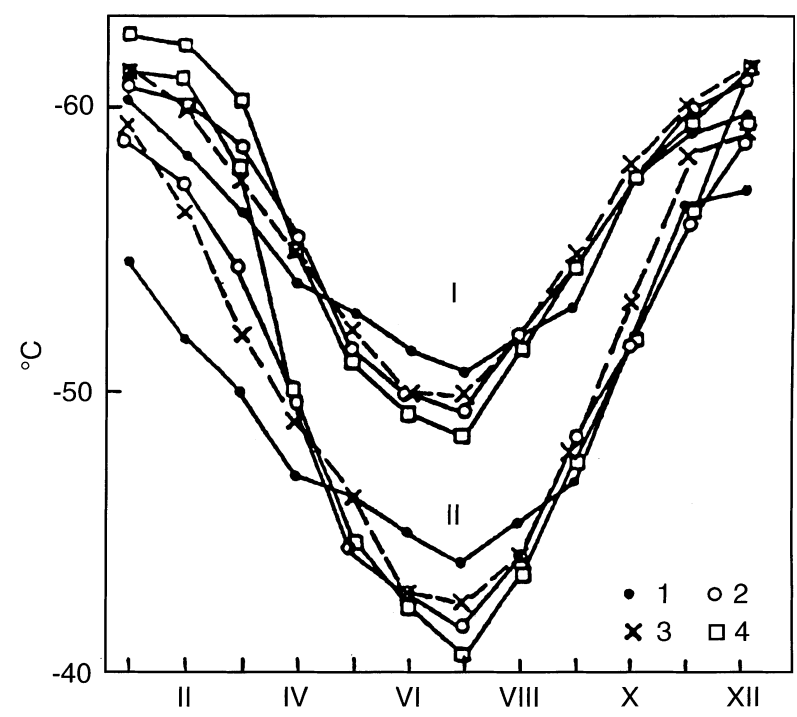

Fig. 2. Temperature of lower (I) and upper (II) bounds of tropopause over the Arctic Basin: (1) $70^{\circ}-75^{\circ} \mathrm{N}$; (2) $75^{\circ}-80^{\circ} \mathrm{N}$; (3) $80^{\circ}-85^{\circ} \mathrm{N}$; (4) $85^{\circ}-90^{\circ} \mathrm{N}$

Annual evolution of the tropopause height in high latitudes (Fig. 3) points to the existence of two maxima and two minima above the Arctic Basin. However, the moments of their appearance differ by 1-2 months from the data published in Gaigerov (1964) and Mahover (1983). The major maximum is observed in August, the secondary one - except for the region $75^{\circ}-80^{\circ} \mathrm{N}-$ in December-January. Minimal monthly average values of lower and upper tropopause heights are observed within the entire Arctic Basin in April and October.

The tropopause upper and lower bounds from April till October decrease northwards. The annual amplitudes of its upper and lower bound heights are also subjected to latitudinal variations, namely $1.35-1.17 \mathrm{~km}$ and $0.61-0.79 \mathrm{~km}$ within the $70-90^{\circ} \mathrm{N}$ latitudinal strip.

Monthly average tropopause thickness and vertical temperature gradient within its bounds were calculated for the entire Arctic Basin on the basis of aerological

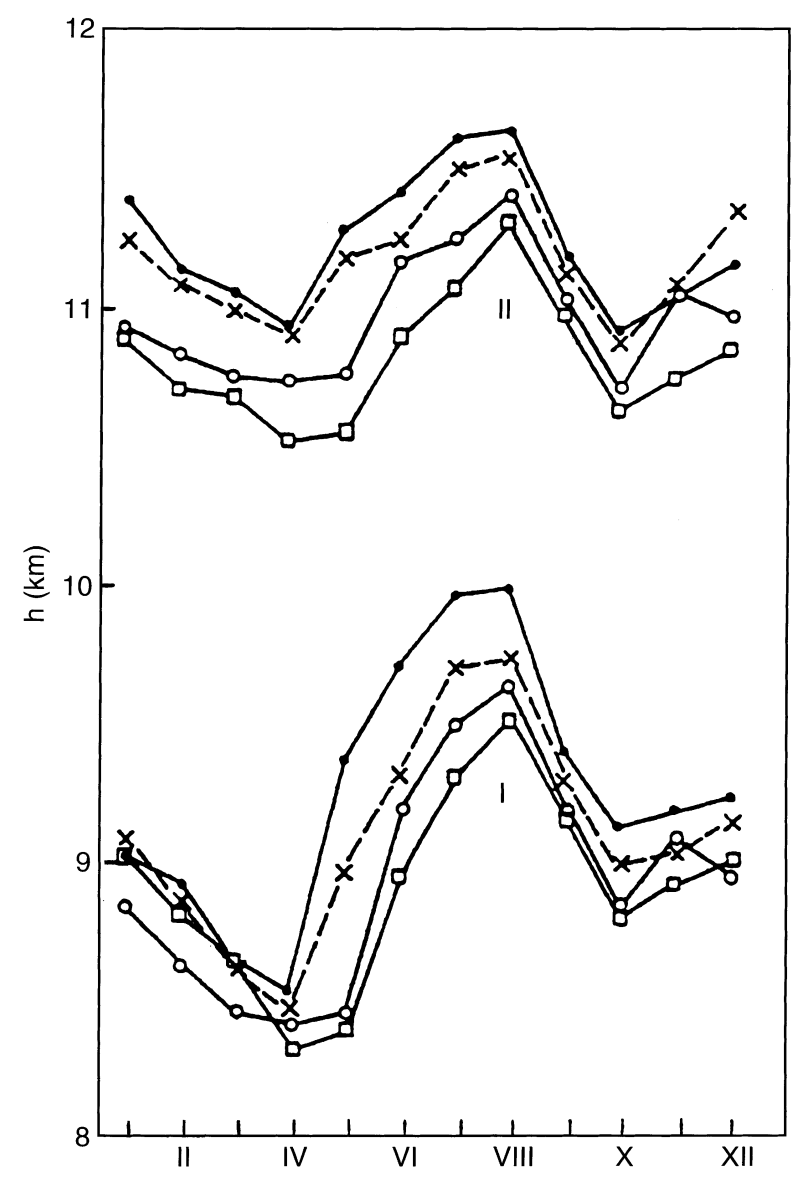

Fig. 3. The height of lower (I) and upper (II) bounds of tropopause over the Arctic Basin: (1) $70^{\circ}-75^{\circ} \mathrm{N}$; (2) $75^{\circ}-80^{\circ} \mathrm{N}$; (3) $80^{\circ}-85^{\circ} \mathrm{N}$; (4) $85^{\circ}-90^{\circ} \mathrm{N}$

measurements completed at drifting stations over a time-interval of 38 years.

In the distribution of tropopause thickness $(\Delta h)$ and vertical temperature gradient $(\gamma)$, seasonal and latitudinal differences are discovered (Table 2). Annual evolution of tropopause thickness above the Polar Ocean has one maximum (in April) and one minimum (in 
Table 2. Annual evolution of mean thickness $(\Delta h \mathrm{~km})$ and vertical temperature gradient $\left(\gamma^{\circ} \mathrm{C} / 100 \mathrm{~m}\right)$ within tropopause layer

\begin{tabular}{|c|c|c|c|c|c|c|c|c|c|c|c|c|c|c|}
\hline \multicolumn{2}{|c|}{ coordinates } & \multirow[t]{2}{*}{ parameter } & \multirow[t]{2}{*}{ I } & \multirow[t]{2}{*}{ II } & \multirow[t]{2}{*}{ III } & \multirow[t]{2}{*}{ IV } & \multirow[t]{2}{*}{ V } & \multirow[t]{2}{*}{ VI } & \multirow[t]{2}{*}{ VII } & \multirow[t]{2}{*}{ VIII } & \multirow[t]{2}{*}{ IX } & \multirow[t]{2}{*}{$\mathrm{X}$} & \multirow[t]{2}{*}{ XI } & \multirow[t]{2}{*}{ XII } \\
\hline${ }^{\circ} \mathrm{N}$ & ${ }^{\circ} \mathrm{E}, \mathrm{W}$ & & & & & & & & & & & & & \\
\hline \multirow[t]{2}{*}{$75-80$} & $150 \mathrm{E}-$ & $\Delta h$ & 2.09 & 2.30 & 2.40 & 2.42 & 2.39 & 2.04 & 1.90 & 1.88 & 1.67 & 1.80 & 1.99 & 1.93 \\
\hline & $175 \mathrm{E}$ & $\gamma$ & -0.09 & -0.16 & -0.22 & -0.24 & -0.32 & -0.34 & -0.38 & -0.43 & -0.45 & -0.34 & -0.22 & -0.13 \\
\hline \multirow[t]{2}{*}{$75-80$} & $175 \mathrm{E}-$ & $\Delta h$ & 2.34 & 2.37 & 2.60 & 2.72 & 2.31 & 2.05 & 1.93 & 1.91 & 1.98 & 2.06 & 2.21 & 2.32 \\
\hline & $160 \mathrm{~W}$ & $\gamma$ & -0.07 & -0.13 & -0.22 & -0.23 & -0.24 & -0.32 & -0.36 & -0.38 & -0.34 & -0.25 & -0.18 & -0.11 \\
\hline \multirow[t]{2}{*}{$80-85$} & $120 \mathrm{E}-$ & $\Delta h$ & 1.94 & 2.03 & 2.21 & 2.35 & 2.21 & 2.06 & $1.77-$ & 1.65 & 1.67 & 1.80 & 1.90 & 1.92 \\
\hline & $160 \mathrm{~W}$ & $\gamma$ & -0.07 & -0.16 & -0.24 & -0.26 & -0.30 & -0.39 & -0.44 & -0.49 & -0.47 & -0.36 & -0.21 & -0.11 \\
\hline \multirow[t]{2}{*}{$80-85$} & $160 \mathrm{E}-$ & $\Delta h$ & 2.15 & 2.24 & 2.28 & 2.40 & 2.26 & 1.92 & 1.89- & 1.75 & 1.85 & 1.89 & 1.91 & 2.05 \\
\hline & $160 \mathrm{~W}$ & $\gamma$ & -0.09 & -0.12 & -0.21 & -0.24 & -0.31 & -0.38 & 0.40 & -0.45 & -0.39 & -0.30 & -0.22 & -0.13 \\
\hline \multirow[t]{2}{*}{$80-85$} & $120 \mathrm{~W}-$ & $\Delta h$ & 2.13 & 2.27 & 2.39 & 2.65 & 2.13 & 2.03 & $1.83-$ & 1.79 & 1.84 & 1.86 & 1.99 & 2.03 \\
\hline & $160 \mathrm{~W}$ & $\gamma$ & -0.10 & -0.12 & -0.18 & -0.25 & -0.34 & -0.36 & 0.42 & -0.46 & -0.41 & -0.33 & -0.20 & -0.12 \\
\hline \multirow[t]{2}{*}{$85-90$} & $90 \mathrm{E}-$ & $\Delta h$ & 1.94 & 1.97 & 2.01 & 2.27 & 2.20 & 2.02 & $1.83-$ & $1.80-$ & 1.83 & 1.84 & 1.86 & 1.88 \\
\hline & $90 \mathrm{~W}$ & $\gamma$ & -0.08 & -0.09 & -0.11 & -0.20 & -0.29 & -0.37 & 0.41 & 0.44 & -0.43 & -0.34 & -0.24 & -0.12 \\
\hline \multirow[t]{2}{*}{$85-90$} & $90 \mathrm{~W}-$ & $\Delta h$ & 1.91 & 1.98 & 2.06 & 2.31 & 2.10 & 1.85 & $1.65-$ & 1.60 & 1.85 & 1.87 & 1.89 & 1.90 \\
\hline & $90 \mathrm{E}$ & $\gamma$ & -0.07 & -0.07 & -0.11 & -0.24 & -0.28 & -0.42 & 0.48 & -0.50 & -0.38 & -0.27 & -0.13 & -0.09 \\
\hline
\end{tabular}

August-September). The second $\Delta h$ maximum in October and minimum in January (Mahover, 1983) were not revealed on the basis of the 1954-1991 data set. The existence of a tropopause thickness maximum in April is linked with winter interlatitudinal exchange decrease and with slight air warming caused by radiation in the upper troposphere and stratosphere above the icecovered and snow ocean surface.

Frequency and thickness of near-surface inversions (Nagurny, 1995), as well as the solidity of the ice cover, diminish in summer due to warming of the underlying surface. Increases in convection intensity and water vapour concentration lead to the growth of long-wave atmospheric radiation. According to Chernigovsky and Marshunova (1965), backward atmospheric radiation in August is 1.82 times higher than in January. Significant growth of long-wave radiation within the tropopause inverse layer leads to a significant decrease in its thickness with minimum in August-September.

Inverse evolution of monthly average air temperature above the Arctic Basin in the tropopause layer is observed throughout an entire observational period (Table 2). The variation in thickness of the tropopause layer due to radiative factors occurs faster than the difference in temperature change between the tropopause upper and lower bounds (Mahover, 1983). Therefore, maximum negative values of vertical temperature gradient as well as minimum values of tropopause thickness are noticed in August-September. During the polar night, absolute $\gamma$ values within the tropopause layer are minimal (between $-0.07^{\circ}$ and $-0.10^{\circ} \mathrm{C}$ per $100 \mathrm{~m})$.
Interannual changes in the Arctic tropopause parameters were compared in the region between $75^{\circ}$ and $90^{\circ} \mathrm{N}$. Characteristics of interannual variability of tropopause parameters are given in Table 3 and Fig. 4 (Alekseev et al., 1994).

Table 3 demonstrates an increase in the tropopause lower boundary in January and July during the period 1954-1991, and a decrease in the upper boundary height. Hence the temperature of the lower and upper boundaries of the tropopause decreased. If the temperature decrease was only induced by the altitude changes $h_{\mathrm{L}}$ and $h_{\mathrm{H}}$ given in Table 3 , then the temperature gradient within the tropopause layer should remain roughly constant, while on the contrary, the actual mean value of the meteorological vertical temperature gradient clearly exhibits a tendency to increase from year to year. This indicates a cooling of the lower boundary of the tropopause, which may be the result of an increase in the meteorological vertical gradient of underlying upper-troposphere temperature. The latter contributes to a decrease in vertical hydrostatic stability of the polar troposphere and to an activation of convective processes. As a result the tropopause lower boundary rises, in congruence with a real trend.

\section{Conclusions}

Summing up the results of the analysis of the North Pole drifting station aerological data set produces the following conclusions:

Table 3. Estimates of tropopause parameters (by linear trend) in the Arctic atmosphere 1954-1991. Note that $h_{\mathrm{L}, \mathrm{H}}$ is the height of lower and upper boundaries of tropopause $(\mathrm{km}), t_{\mathrm{L}, \mathrm{H}}$ is the temperature on the lower and upper boundaries of tropopause, $\Delta h=h_{\mathrm{H}}-h_{\mathrm{L}}$ is the thickness of tropopause $(\mathrm{km})$ and $\gamma$ is the gradient in the tropopause layer $\left({ }^{\circ} \mathrm{C} / \mathrm{km}\right)$

\begin{tabular}{lllllll}
\hline month & \multicolumn{1}{l}{ tropopause parameters } & & & & \\
\cline { 2 - 7 } & $h_{\mathrm{L}}$ & $h_{\mathrm{H}}$ & $t_{\mathrm{L}}{ }^{\circ} \mathrm{C}$ & $t_{\mathrm{H}}{ }^{\circ} \mathrm{C}$ & $\Delta h$ & \\
\hline January & +0.27 & -0.78 & -2.4 & -0.9 & -1.05 & -0.09 \\
July & +0.38 & -0.24 & -3.2 & -2.5 & -0.62 & -0.18 \\
\hline
\end{tabular}



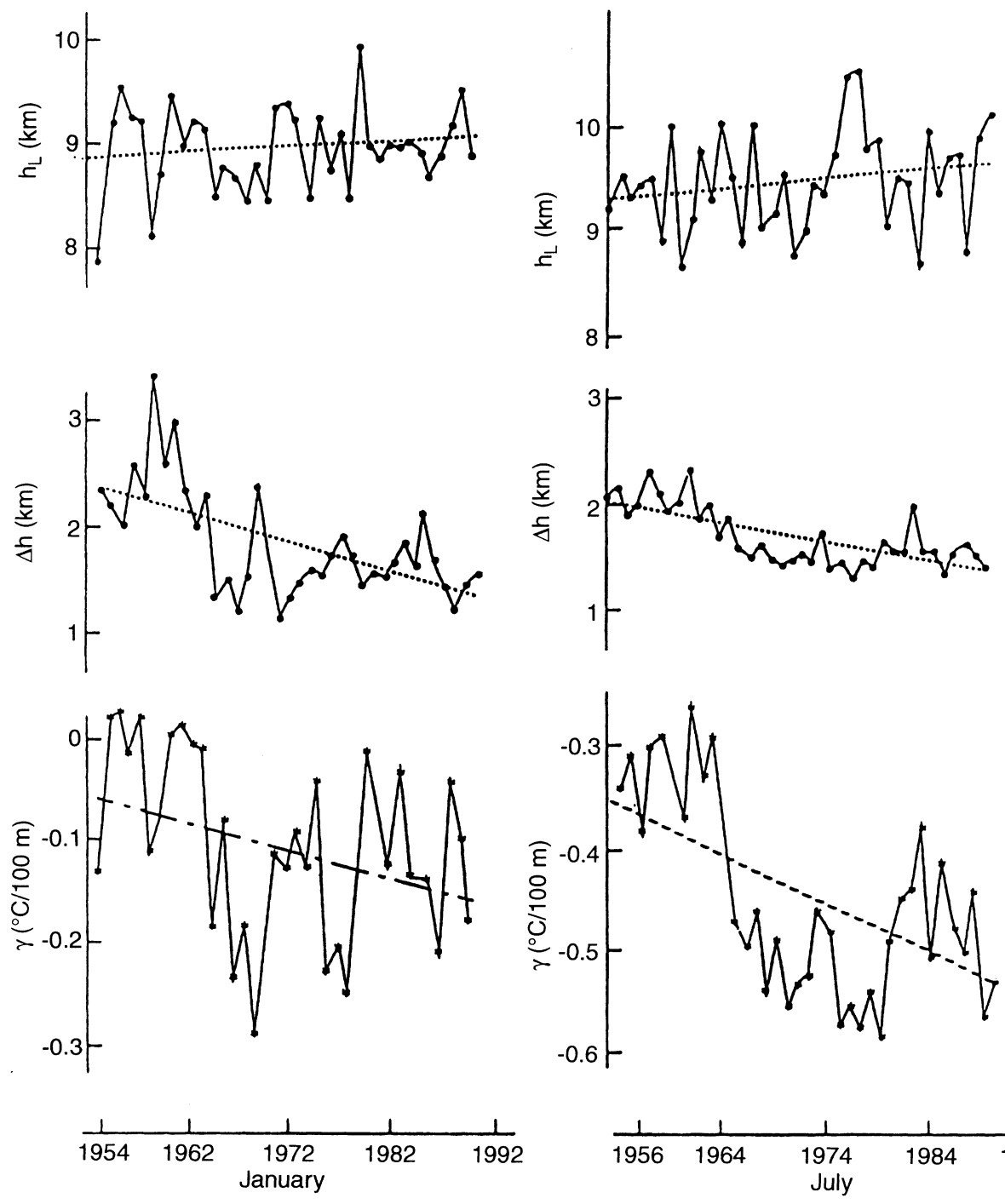

Fig. 4. Interannual variability of tropopause parameters in the Arctic during 1954-1991 $\left(\Delta h=h_{\mathrm{H}}-h_{\mathrm{L}} ; h_{\mathrm{H}}-\right.$ height of upper bound; $h_{\mathrm{L}}$ - height of lower bound; $\gamma$-vertical temperature gradient of tropopause)

1. Annual amplitude of air temperature at the tropopause level within the latitudinal strip $70^{\circ}-90^{\circ} \mathrm{N}$ increases polewards. The band of its values could be estimated as $10^{\circ}-14^{\circ} \mathrm{C}$ and $13^{\circ}-21^{\circ} \mathrm{C}$ for lower and upper bounds, respectively.

2. Annual amplitudes of upper and lower tropopause heights within the belt $70^{\circ}-90^{\circ}$ depend on the latitude and vary within the margins of $1.95-1.17 \mathrm{~km}$ and $0.61-0.79 \mathrm{~km}$, respectively.

3 . Within the annual cycle, external monthly average temperature values at the tropopause bounds to the north of $70^{\circ} \mathrm{N}$ are observed near the pole, and extremal heights near $70^{\circ} \mathrm{N}$ latitude.

4. Annual evolution of the Arctic tropopause thickness is characterized by a single maximum (in April) and a single minimum (in August-September). Seasonal variation of tropopause thickness does not exceed $1.12 \mathrm{~km}$.

5. Minimal absolute values of vertical temperature gradient (from -0.07 to $-0.09{ }^{\circ} \mathrm{C}$ per $100 \mathrm{~m}$ ) are observed in January, while the maximal ones (from -0.36 to $-0.50{ }^{\circ} \mathrm{C}$ per $100 \mathrm{~m}$ ) between July and September.
6. A long-term trend of tropopause thickness and vertical temperature gradient is discovered. Since 1965 , the monthly average vertical temperature gradient has remained negative in all months. This fact points to the formation of permanent inversion in this transient layer, accompanied by the monotonic decrease in tropopause thickness from 1954 to 1991.

Acknowledgements. The Editor-in-chief thanks F. Bertin for his help in evaluating this paper.

\section{References}

Alekseev, G. V., A. P. Nagurny, and A. A. Timerev, Interannual variability of tropopause characteristics in the Arctic, Rep. Acad. Sci. Russia, 339, 243-245, 1994.

Chernigovsky, N. T., and M. S. Marshunova, Climate of Russian Arctic (radiative conditions) (in Russian), Hydrometeoizdat, Leningrad, 1965.

Commission for aerology, Abridged final report of the second session, Paris, 18th June - 5th July, WMO, Geneva, N 65, RP.27, 1957.

Danielsen, E. F., Stratospheric-tropospheric exchange, based upon radioactivity, ozone and potential vorticity, J. Atmos. Sci., 25, 502-518, 1968. 
Giagerov, S. S., Aerology of polar regions (in Russian), Hydrometeoizdat, Leningrad, 1964.

Goldied, N., J. G. Moore, and E. E. Austin, Upper air temperature over the world, Geophys. Mem., 13, 1958.

Hofmann, D. J., J. M. Rosen, and T. E. Pepin, Influence of the tropopause height on the global increase in ozone, J. Appl. Meteorol., 13, 734-737, 1974.

Holton, J. R., P. H. Hayes, M. E. Mcintyre, A. R Douglass, R. B. Rood, and L. Pfister, Stratosphere-troposphere exchange, Rev. Geophys., 33, 403-439, 1995.

Karol, I. L., Radioactive isotopes and global atmospheric transport (in Russian), Hydrometeoizdat, Leningrad, 1972.

Mahover, Z. M (Ed.), Atlas of climatic tropopause characteristics over the northern hemisphere (in Russian), Hydrometeoizdat, Leningrad, 1973.
Mahover, Z. M., Climatology of the tropopause (in Russian), Hydrometeoizdat, Leningrad, 1983.

Methodical notes. Radiative correction terms to radiosondes $R Z$ 049, A22-RK31 (in Russian), 25, Hydrometeoizdat, Moscow, 1960.

Nagurny, A. P., Space-time distribution of temperature inversions in the Arctic atmospheric boundary layer, Ann. Geophysicae, 13, 1087-1092, 1995.

Timerev, A. A., A. P. Nagurny, S. A. Egorov, and E. Y. Medvedchenco, Climate characteristics of the height and temperature of the tropopause over the Arctic Basin, Meteorol. Hydrol., 6, 39-47, 1994. 